\title{
The status survey on high teacher-student relationship in city and Influencing Factors
}

\author{
Yunfeng TANG \\ School of Public Health \\ Weifang Medical College \\ Weifang, 261053, China
}

\begin{abstract}
High school students in a city in Shandong province as the research object in this paper, we investigates the actuality and influence factors analysis on the relationship between teachers and students, mainly through questionnaire and interview, the results showed that in city high school, about $5 \%$ of the teacher-student relationship in tension and 1 $52 \%$ in general, $\mathbf{4 3 \%}$ is good; the teacher-student relationship is affected by the students' gender, grade, character, type, parents' education level, their health level and academic performance. So in view of the factors that affect the relationship between teachers and students, we should take reasonable countermeasures, promote the construction of a harmonious relationship between teachers and students, so as to realize the comprehensive and healthy development of students' physical and mental quality, eventually improve the education quality of teaching.
\end{abstract}

Keywords- high school; the relationship between teachers and students; the status survey; influencing factors

\section{INTRODUCTION}

Teacher-student relationship is a special relationship that teachers and students form and build through the interaction and impact in the co- educational, teaching process. ${ }^{[1]}{ }^{[2]}$ Teacher-student relationship is a relationship system composed by multidimensional relationship. Chinese and foreign educators has been devoted to studying the major issue that how to understand and grasp the nature and characteristics of teacher-student relationship. High school is the crucial stage of life, physical and psychological maturity. Many research results show that high school students' interpersonal situation is not optimistic, some students have different degrees of psychological problems ${ }^{[3]}{ }^{[4]}$, therefore, the research on psychological health problem of high school students this special crowd of group is paid attention to by the community day by day.

The purpose of this article is to investigates the actuality and influence factors analysis on the teacher-student relationship taking the high school students in the city in Shandong province as the research object, aimed to promote the construction of a harmonious relationship between teachers and students, so as to realize the comprehensive and healthy development of students' physical and mental quality, eventually improve the education quality of teaching.

\section{SURVEY DESIGN}

Study purpose: investigate the status of teacher- student relationship in a city in Shandong province, explore the factors that affect the teacher- student relationship and provide theoretical basis for the construction of a harmonious teacher- student relationship

Respondents choice: the survey began in the first half of 2014, adopted the method of stratified cluster random sampling, selecting the city 3 high school 545 students in grade three, the investigators unified questionnaires and read out the matters needing attention. When they completed, the investigators take back the questionnaire on the spot.

questionnaire design: adopting to the self- prepared 《the basic information questionnaire form 》 and 《the teacherstudent relationship quiz》 made by Wu Qingxiang etc. 《the basic information questionnaire form 》 include: (1) individual situation of the respondent: age, sex, blood type, nationality, place of residence, and so on (2) the influence factors: genetic factors (including parents health, etc.), family factors (including parents' educational level, whether family relationship is harmonious or not, parents' marriage, whether the one-child etc.), oneself personality factors (individual personality type), life events (experience negative life events such as the lost their loved ones or not, history of suffering from serious illness, and so on), learning pressure, relationship problems, etc., comprehensively considering the factors that may affect the relationship between teachers and students. The teacher-student relationship test questionnaire include 18 questions, if the answer is yes, recording 1 point. If the answer is no, recording -1 point. All projects accumulative total score between 8 to 18 points, shows the teacher-student relationship is very nervous. Total score between 8 to 7 points, shows the teacher-student relationship is not so good; Total score between $18 \sim 9$ points, shows the teacher-student relationship is OK.

The questionnaire can be divided into three groups, and each group contains six projects. They are: group A: 1, 4, 7, $10,13,16$, and the total score of group A shows the tension level in teaching process, $4 \sim 6$ points, show very nervous; $3 \sim 3$ points, show a little bit nervous; - $6 \sim-4$ points shows that it don't stress; Group B: 2, 5, 8, 11, 14, 17, the total score of group B shows the degree of confusion in the emotional distance, $3 \sim 6$ points, shows very confused; -3 to 2 points, suggests that some confusion; - 6 to 4 points, which indicates 
that basically no confusion; Group C: $3,6,9,12,15,18$, the total score of group $\mathrm{C}$, shows the degree of feeling the difference status with teacher, $3 \sim 6$ points, shows the teacher status difference is big; - 3 to 2 points, difference is a little; 6 to 4 points, expresses no differences in status. With Internal consistency test, the result shows that the questionnaire of the teacher-student relationship to detect the value of the Cronbach a is 0.907 , so the reliability of the scale is better and can use the questionnaire to test the relationship between teachers and students.

Organization and implementation of the survey

(1) The investigator unified training before the survey, before the formal investigation, we make preliminary investigation, and check the feasibility of the survey, finding problems in a timely manner to correct. (2) Before the end of a full investigation, randomly select a questionnaire from survey questionnaires for review, and check the accuracy and dependability of the survey.

Statistical methods: we will check the returned questionnaires.EXCEL2003 is adopted to establish the sample database. We complete the whole process of statistical analysis using SPSS13.0 software.

\section{THE RESULTS OF THE SURVEY AND ANALYSIS}

\section{A. The general situation of study object}

The survey questionnaires were distributed and 545 copies, 530 valid questionnaires were recovered. The effective rate was $97.25 \%$. Among them, the high first year students are 180 people, accounting for 33.96\%; High sophomore students are 200 people, accounting for $37.74 \%$; Grade three students are 150 people, accounting for $28.30 \%$. Boys are 310 people, accounting for $58.49 \%$, girls are 220 people, accounting for $41.51 \%$. City students are 379 people, accounting for $71.51 \%$, the countryside students are 151 people, accounting for $28.49 \%$. Only children have 380 people, accounting for $71.70 \%$, not only children have 150 people, accounted for $28.30 \%$.

1.2.2 The overall situation of the teacher-student relationship

According to the test of the teacher-student relationship made by Wu Qingxiang etc., scoring criteria is: total score between 8 to 18 points, shows the relationship is very nervous. Total score between 8 to 7 points, said the teacherstudent relationship is not so good; Total score between 18 9 points, said the teacher-student relationship can be OK. This scale can be divided into three subscales, respectively is on behalf of the tension degree with teacher in the teaching process, the confusion in emotional distance between the students and teachers and the confusion on the status difference. This survey shows, 530 subjects in total of 26 students between 8 to 18 points, accounting for $4.91 \%$; Total score between $8 \sim 7$ points, 277 students, accounting for $52.26 \%$; Total score between $18 \sim 9$ points of 227 students, accounting for $42.83 \%$. Through the survey on the tension degree with the teachers in the teaching process, 23 students are very nervous, accounting for $4.34 \% ; 175$ students are a little nervous, accounting for $33.02 \%$; 332 students have no stress, accounting for $62.64 \%$. Through the survey on the confusion with the teacher on the emotional distance degree, 96 students are very confused, accounting for $18.11 \% ; 281$ students are a little confused, accounting for $53.02 \%$; Basically no confusion are 153 students, accounting for $28.87 \%$. Through the survey on the degree of difference in status with teachers, 21 students feel great difference with teachers, accounting for $3.96 \%$; 211 students think a little difference, accounted for $39.81 \%$; 298 students are not aware of any differences, accounting for $56.23 \%$.

\section{THE INVESTIGATION OF INFLUENCING FACTORS FOR THE TEACHER-STUDENT RELATIONSHIP}

1) The relation between gender and the teacher-student relationship

The investigation of male and female students in the teacher-student relationship scores results show that the $\mathrm{P}$ value is less than 0.05 after statistical analysis ( $t$ test), which shows there is statistical significance about male students score and female students score in the teacher-student relationship. The female classmate's scoring average is lower than male students, which shows state of the teacher-student relationship of female classmate is better than male students. Reason may be that: the teacher-student relationship has certain relation with boy's and girl's different physiological characteristics, personality psychological characteristics and the social demand for men's and women's different. Generally girls in verbal expression ability is better than boys, one is may be due to innate factors determined, because women in common nerve cells of the brain associated with processing language is more $15 \% \sim 20 \%$ than the male. Female subtle inner gentle, work carefully earnestly, understand others, and can be more patience to listen to others' talk. They easily resonate in the process of communication, so the talk fully reflects the style characteristics of cooperation and interaction. Therefore, women behave better than men when use the language symbol to express their thoughts and inner feelings. It is easier to get along with classmates and teachers, so in finishing the homework, getting along with parents and teacher they are better [5]. On the other hand it also is related to the different social role and social expectations to men and women. In the modern society, women tend to be good at the role of public relations and communication of career. Women are expected to have good language expression ability, but the male than female tend to have more emotional tacitness and independence. Men's personality is treated as "trouble", "naughty", "don't obey the discipline", etc. by the teacher so that the inconsistency between the boy and the teacher is more negative emotion and constraint control. So the boys behave worse than girls in the teacherstudent relationship [6]

\section{B. The relation between grade and the condition of the teacher-student relationship}

Investigation for different grade students the teacherstudent relationship score results show that the $\mathrm{P}$ value is less than 0.05 after single factor variance analysis, then through Dunnett 's method of $\mathrm{t} 3$ multiple comparison results show 
that: the difference of average score in teacher-student relationship of grade one, grade two, grade three students has statistical significance. The results show grade one students have better relationship with teachers than grade two and three. It is close to Shi Xuezhong's reports [7]. Relationship between teachers and students in the grade graduate students is poor than other grades. The reasons for the situation may be from several aspects: the main problems the graduate face is class entrance and entrance pressure always bother them. In the increasingly pressing time and the entrance pressure of the increasingly serious situation, graduated from grade teacher is with often more strict management for the students, which makes the relationship between the students and teachers increasingly nervous. Especially under the current national education system, graduated from grade teacher and students still are sensitive to the result of the examination. All test result as the criterion, students' learning atmosphere is highly tense, so similar problems directly affect the teacher-student relationship of grade graduation. To improve the teacher-student relationship of grade graduation status, on the one hand, rely on system construction by the relevant competent department of education, and we hope to adjust the structure of education system, perfect the education system and other measures to reduce the graduating class of students entrance pressure; on the other hand, as first-line teachers especially graduated grade teacher, at ordinary times they should pay more attention to caring about students, understand students' needs and psychological problem, and make every effort to help students all-round development [8].

\section{The relationship between grade and the condition of teacher-student relationship}

Different grades of students through teacher-student relationship survey scores through single factor variance analysis showed $\mathrm{P}$ values less than 0.05 , then through Dunnett's $\mathrm{t} 3$ multiple comparison results show that: There was statistical significance about the average point's difference between academic excellent students and general student in teacher-student relationship. The students with high grade behave better than poor performance students in teacher-student relationship

\section{The relation between personality type and the teacher- student relationship condition}

The results show the extroverted students perform better than introverted students in dealing with the teacher-student relationship

\section{E. The relation between parents' education level and the condition of the teacher-student relationship}

There is no statistical significance about that parents' education level and the state of the teacher-student relationship through the single factor analysis of variance between groups, but from the teacher-student relationship of each group scores can reflect the higher the education level of the parents, children's state of the teacher-student relationship is relatively better. It may be the reason that high education level parents can solve problems well, and reduce the child's negative emotions, so improve the parents' educational level is helpful to improve the teacher-student relationship of the students. Degree of education level of parents affects their children's life, learning, relation, and also indirectly affects the teacher-student relationship of the children. Parents with low education level, think that education is completely the school and the teacher education, handing their right for the child's education to the school and the teacher. Let the teachers manage, which is an irresponsible attitude, they think school as a place to teach children knowledge purely. As long as children acquire knowledge, the teacher uses what kind of method is not important; some students do not obey the discipline. Their parents even think school as a "child look". They think as long as they don't make trouble, it doesn't matter whether to acquire knowledge; some parents don't understand the teacher's work. If the children make mistakes to be criticized by the teacher, they not only don't convince children to accept criticism and correct mistakes, instead adding inflammatory details, even go to school and teachers "reason" These practices are not conducive to children's growth and education. Parents with high education level tend to work actively and cooperate with teacher. They not only attach importance to children's knowledge, also pay attention to the child's attitude to learning, the cultivation of personality and teachers' teaching way. They hope the teacher can provide a democratic, loose, pleasant environment, making the child's rights guaranteed and smooth communication between the teachers and students, the harmonious relationship between teachers and students. Parents hope teachers treat children with kind, careful patience, and hope children can actively cooperate with the teacher's teaching, accept the teacher's criticism, and fully understand the teacher's work [9]. In addition, in the survey we found that both parents especially mother has more influence on children. This is because the mother and the children get along with more time; children tend to give vent to their mother in the state of mind, tell about the truth, and hope to get parents to comfort and help, so mother has more influence on the child than father

\section{$F$. The relation between student's health condition and teacher-student relationship condition}

The survey on the relation between student's health condition and teacher- student relationship condition show that the poorer health students have the relatively tense relationship between teachers and students, especially the students have suffered a serious disease is worse than no serious disease history students $(\mathrm{P}<0.05)$.

\section{CONCLUSIONS}

Teacher-students relationship problem has long been a focus of attention in education theory and practice, and is also one of the most important aspects of the education teaching reform all over the world. Under the present situation of the new curriculum reform, the construction of a harmonious relationship between teachers and students is still a factor cannot be ignored. According to the results of 
the above questionnaire survey, we understand the present situation of urban high school teacher-student relationship, recognize the problems of teacher-student relationship, and analyze the reasons for the status existence. The next step should take reasonable measures for the factors affecting the teacher-student relationship, to promote the construction of a harmonious relationship between teachers and students, so as to realize the comprehensive and healthy development of students' physical and mental quality, eventually improve the education quality of teaching.

\section{Reference}

[1] He Xiaoyan, Zhang Li, Guo Cheng, etc. High school teachers and students relations, the relationship between coping styles and their research $[\mathrm{J}]$. Journal of southwest normal university (natural science edition), 2006, 31 (1) : 152-157.

[2] Jin-yu li. The practice of the theory of good relationship between teachers and students to construct strategy [J]. Journal of northwest normal university, 2000 (6) : 33-37.
[3] The theory and practice to construct the new relationship between teachers and students study. Suzhou university [D]. Suzhou: 2008.

[4] Wan Xiaoling. Buildthe teacher-student relationshipof the 21st century [J]. Journal of jiangxi education. 2002, 13 (a 14).

[5] Zhang Jing. Vocational colleges students' interpersonal relationship present situation investigation and analysis [J]. Journal of mudanjiang normal university journal (philosophy club edition), 2010, (1) : 114117.

[6] Dai Binrong, Yin Guoen. Rural school high school students interpersonal situation mainly study [J]. Journal of psychology and behavior research, 2004, 2 (4) : 622-625.

[7] Shi Xuezhong, He Chunhua, Zhang Huanfeng, etc. Zhengzhou middle school students learning anxiety research [J]. Journal of school health in China, 2001, 22 (2) : 117-118.

[8] Cai Jun. Under the background of new curriculum reformthe teacherstudent relationshipstudy [D]. Xinxiang, henan normal university, 2009.

[9] Xu Xuejun, Li Zhenghong, Wang wen. Survey aboutthe teacherstudent relationshipof primary and secondary schools and thinking $[\mathrm{J}]$. Journal of education scientific research. 2005 (5) : 28-31. 